\title{
Mindfulness-Based Program for Infertility: efficacy study
}

\author{
Ana Galhardo, Ph.D.., ${ }^{a, b}$ Marina Cunha, Ph.D., ${ }^{a, b}$ and José Pinto-Gouveia, M.D., Ph.D. \\ a Instituto Superior Miguel Torga and ${ }^{b}$ Faculty of Psychology and Educational Sciences of the University of Coimbra, \\ Coimbra, Portugal
}

Objective: To present and determine the impact of the Mindfulness-Based Program for Infertility (MBPI).

Design: Controlled clinical trial.

Setting: University research unit.

Patient(s): Fifty-five infertile women completed the MBPI, and 37 infertile women were assigned to a control group.

Intervention(s): The MBPI includes 10 weekly sessions, in a group format, with a duration of about 2 hours each (men attend three sessions).

Main Outcome Measure(s): Standardized measures of depression, state anxiety, entrapment, defeat, internal and external shame, experiential avoidance, mindfulness, self-compassion, and infertility self-efficacy were endorsed pre- and post-MBPI.

Result(s): The MBPI group and the control group were shown to be equivalent at baseline. By the end of the MBPI, women who attended the program revealed a significant decrease in depressive symptoms, internal and external shame, entrapment, and defeat. Inversely, they presented statistically significant improvement in mindfulness skills and self-efficacy to deal with infertility. Women in the control group did not present significant changes in any of the psychological measures, except for a decrease in self-judgment. Conclusion(s): Increasing mindfulness and acceptance skills, as well as cognitive decentering from thoughts and feelings, seem to help women to experience negative inner states in new ways, decreasing their entanglement with them and thus their psychological distress. Data suggest that the MBPI is an effective psychological intervention for women experiencing infertility. (Fertil Steril ${ }^{\circledR}$ 2013;100: 1059-67. (C)2013 by American Society for Reproductive Medicine.)

Key Words: Mindfulness, acceptance and commitment therapy, infertility, psychopathology

Discuss: You can discuss this article with its authors and with other ASRM members at http:// fertstertforum.com/galhardoa-mindfulness-infertility-psychopathology/

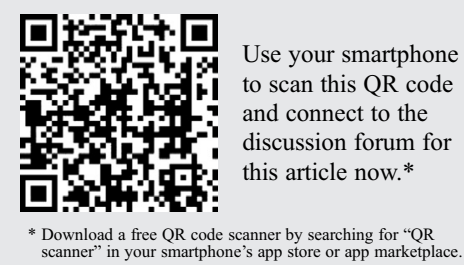

I nfertility presents many challenges to infertile couples. It has been described as a stressful condition not only from a medical perspective but also in terms of psychological burden, with couples stating that it corresponds to a very demanding life crisis (1-3). Emotional consequences tend to arise from the inability to conceive a child, affecting each partner's personal life and the couples' life. Studies focusing on the psychological consequences of infertility have produced mixed results (4-10). Most couples are able to adjust and cope with infertility, but others present problematic emotional responses such as depression and anxiety $(11,12)$.

Over the past few decades, psychological interventions have been developed to address the psychological consequences of infertility. According to Boivin (13), positive results from psychological interventions can occur in feelings of anxiety, tension, and worry, more than in depressive symptoms. This investigator states that interventions that emphasize education and skills training are more

Received February 25, 2013; revised May 17, 2013; accepted May 22, 2013; published online June 27, 2013.

A.G. has nothing to disclose. M.C. has nothing to disclose. J.P.-G. has nothing to disclose.

This research was supported by a grant (SFRH/BD/68392/2010) from the Portuguese Foundation for Science and Technology (to A.G.).

Reprint requests: Ana Galhardo, Ph.D., Instituto Superior Miguel Torga, Largo da Cruz de Celas, no. 1, 3000-132 Coimbra, Portugal (E-mail: anagalhardo@ismt.pt).

effective than those addressing emotional expression and support. Another study reviewing results from group interventions and individual/ couple psychotherapy (14) found that both intervention formats tend to decrease anxiety and depression. In another meta-analysis, Hammerli, Znoj, and Barth (15) analyzed 21 controlled studies about the efficacy of psychological interventions in terms of mental health indicators and pregnancy rates. No significant effects were found regarding mental health, but significant effects were found in pregnancy rates in couples who were not using assisted reproductive technology. These investigators also suggest that women may benefit more from psychological interventions when compared with their male partners. Recently, the Integrative Body-Mind-Spirit intervention has 
proved successful at improving the psychosocial and spiritual well-being of women undergoing their first IVF treatment cycle (16). Domar and colleagues examined the impact of a group mind/body intervention on pregnancy rates in IVF patients and found that participation in such a program increased pregnancy rates for cycle 2, but mental health variables were not studied (17). Another study conducted by Korszycki and colleagues pointed out that interpersonal psychotherapy may be a promising treatment for depressed infertile women, but they argue that subsequent studies are needed to support these results (18).

Several mindfulness-based interventions have been applied and proved effective in numerous health problems such as chronic pain, cancer, anxiety disorders, depression, and so on (19), but to our knowledge a mindfulness-based program specifically addressing infertility has not been developed until now.

Considering that infertile patients may also benefit from such an approach, the Mindfulness-Based Program for Infertility (MBPI) was developed and studied. The MBPI is based on the Mindfulness-Based Program for Stress Reduction (20), the Mind/Body Program for Infertility (21), and basic principles of acceptance and commitment therapy (ACT) (22). It is a structured group intervention targeting infertile women that aims to cultivate mindfulness and acceptance, helping them to move in a chosen and valued life direction.

The MBPI is intended to develop willingness/acceptance through a process of contacting the present moment and being in touch with the unfolding experience in an open and nonjudgmental way. This can be reached by mindfulness practice, bringing awareness to internal and external experiences as they occur in the moment (23). Another important skill learned during the MBPI is cognitive defusion or cognitive decentering. Recognizing that our mind tends to create stories about our lives, it is important to help people to become aware of their story as a story instead of a set of "truths" (24). In other words, it involves distancing from the mind and noticing the story it is telling rather than getting absorbed in it (25).

Furthermore, attitudes of kindness, curiosity, and willingness to be present with the unfolding experience are promoted, as well as the ability to recognize our own experiences as part of the larger human experience.

One of the main goals of MBPI is to promote psychological flexibility/acceptance. This is intended to be achieved through mindfulness practice but also through the use of metaphors such as "the mind as a radio always on" and "the coach and passengers" (22) and through emphasizing the importance of values clarification and committed action. These metaphors are derived from ACT and support the embracing of a new attitude towards private events, promoting their observation, decentering, and nonreacting. The exercise "the pain in my head" (26) is also intended to promote acceptance, willingness, and openness to painful thoughts without trying to suppress, modify, or control them.

The aim of the current study is to present data on the efficacy of the MBPI in a sample of infertile women pursuing medical treatment for their infertility.

\section{MATERIALS AND METHODS}

\section{Participants}

Participants were women who answered a recruitment announcement posted at the Portuguese Fertility Association (patients association) website. The Executive Committee of this association evaluated and approved the study. Inclusion criteria were age (18 years or older) and an infertility medical diagnosis. Participants were all married or living with a partner in a heterosexual relationship (Portuguese legal requirements for access to infertility consultations).

A total of 102 women answered the post. Sixty-one took part in the MBPI group, and 41 integrated the control group. One woman in the MBPI group (1.6\%) gave up her participation before the admission interview for professional reasons. After completing the interview, five women (8.3\%) dropped out from the study (two for professional reasons, one for marital reasons, one for family reasons, and one for unknown reasons). In the control group there was a dropout rate of $12.2 \%$ for unknown reasons. Thus, the MBPI was applied in five groups (two in Lisbon, two in 0'Porto, and one in Coimbra), for a total of 55 participants. The control group was composed of 37 women. These women answered the recruitment announcement but lived in places where the MBPI sessions were not scheduled. Women in both groups presented a primary infertility diagnosis.

\section{Instruments}

Before and after the MBPI (10-week interval), the following set of self-report measures was completed by all the subjects:

Beck Depression Inventory (BDI; 27-29)-BDI is a well-known self-report measure for the assessment of depressive symptoms. In this study we found a Cronbach alpha of .85 in the MBPI group and of .91 in the control group.

State Anxiety Inventory form Y (STAI-Y $1 ; 30,31)$-In this study, we used the state anxiety subscale that captures the way subjects are feeling in the moment they are answering. The Cronbach alpha found for STAI-Y1 was .93 in the MBPI group and .95 in the control group.

Others As Shamer (OAS; 32, 33)-This 18-item scale measures external shame (global judgments of how people think others view them). A Cronbach alpha of .93 was found in both the MBPI group and the control group.

Experience of Shame Scale (ESS; 33, 34)-The ESS is a 27-item questionnaire assessing feelings of shame around three key domains of self: character, behavior, and body. In this study, a Cronbach alpha of .96 was found in the MBPI group and of .95 in the control group.

Entrapment Scale (EE; 35, 36)-The EE assesses external entrapment (perception of things in the outside world that induce escape motivation) and internal entrapment (escape motivation triggered by internal thoughts and feelings). In the current study, both subscales presented a Cronbach alpha of .92 in both groups.

Defeat Scale (DS; 35, 37)-This is a 16-item measure of the sense of failed struggle and losing rank. In the MBPI group, a Cronbach alpha of .92 was found, and in the control group it was .96. 
Acceptance and Action Questionnaire II (AAQ II; 38, 39)-AAQ-II is a seven-item measure that assesses psychological inflexibility/experiential avoidance. In the current study, the AAQ-II presented a Cronbach alpha of .85 in both groups.

Self-Compassion Scale (SCS; 40, 41)-SCS is a measure of self-compassion that comprises a self-judgment subscale and a self-compassion subscale. The first one corresponds to the sum of self-criticism, isolation, and overidentification and showed a Cronbach alpha of .90 in the MBPI group and of .93 in the control group. The second corresponds to the sum of self-kindness, common humanity, and mindfulness and presented a Cronbach's alpha of .92 in the MBPI group and of .90 in the control group.

Infertility Self-Efficacy Scale (ISE; 42, 43)-ISE is an instrument aimed at measuring infertile patients' perception of their capability to use their own cognitive, emotional, and behavioral abilities for dealing with infertility and medical treatment. The ISE presented a Cronbach alpha of .95 in both the MBPI group and the control group.

Frieburg Mindfulness Inventory (FMI; 44)-FMI is a questionnaire measuring mindfulness skills. It proved to be sensitive to change and can also be used with subjects without previous meditation practice. In this study, the FMI showed a Cronbach alpha of .77 (it was completed by a subgroup of 30 women in the MBPI group).

A semistructured clinical interview was used for MBPI admission. This interview allows the gathering of demographic and clinical data and screening for severe psychopathology.

\section{Procedures}

The study was evaluated and approved by the Scientific Committee of the Faculty of Psychology and Educational Sciences of the University of Coimbra. It was also approved by the Portuguese Foundation for Science and Technology and, as mentioned before, by the Portuguese Fertility Association board. The aims of the study, inclusion criteria, participants' role, researchers' obligations, and procedure to participate (contact the first author by e-mail) were explained in the recruitment post. Women in the control group answered this post but did not live in Lisbon, 0'Porto, or Coimbra and could not attend the MBPI sessions (they agreed to join the control group and were given the opportunity to participate in future editions). Clinical information regarding infertility was provided by the participants (there was no consulting of medical records). All the subjects gave their written informed consent, and participants in the MBPI group also signed a pregnancy policy statement.

Participants in both groups completed the set of self-report measures at baseline and after the MBPI (the assessment protocol took about 30 minutes to complete). Participants in the MBPI group also attended a structured clinical interview. The assessment protocol was delivered to the participants in the MBPI group during the admission interview and at the end of the last MBPI session and was completed at home. It was then returned to the research team by mail. In the control group the assessment protocol was sent and returned by mail (stationary post envelopes were provided).
The MBPI includes 10 weekly sessions of 2 hours each, except for one of the sessions that lasts for one day. It is a structured psychosocial intervention program, with a group format (maximum 15 women). Male partners are invited to participate in three sessions. Sessions were led by the first author who is an experienced clinical psychologist with training in mindfulness-based approaches, ACT, and psychological interventions for infertile patients.

Support materials are provided, including a Participant's Manual and an audio CD with mindfulness meditation instructions. The Participant's Manual consists of a set of handouts that cover various topics (definition of mindfulness, the importance of being in the present moment, instructions for mindfulness practice, healthy behaviors, copies of "progress notes," and forms for the exercises).

The audio CD presents an introductory note in which basic aspects of mindfulness practice are revisited (the importance of regular practice, of body posture, of the venue for practice). Several instructions for mindfulness meditation are also available: "body scan" $(20,45-47)$, "three minutes breathing space" (45), "sounds and thoughts meditation" (45), "being in the present moment" $(46,48)$, "inviting a difficulty" (49), "being where we already are" (26), "leaves in the stream" (50), and "mountain meditation" (51). Each of these practices is held during sessions, and participants are invited to repeat it, if possible on a daily basis, during the following week.

A Therapist Manual was also organized, describing the details for conducting each session. This manual includes guidelines and the script for applying the admission structured clinical interview. Suggestions of self-report instruments are also incorporated.

Most of the MBPI sessions follow a similar structure. They begin with a first half-hour of sharing (optional). This time for sharing begins in the second session as the first one follows a different format that is detailed below.

After the first half hour, a formal mindfulness practice is held, followed by sharing how participants felt, what they have noticed, how the experience was for them. The set of formal practices selected for the MBPI is commonly used in mindfulness programs. Informal mindfulness practice is also presented as early as the second session through mindful eating ("the raisin meditation"; 26). The 3-minute breathing space (44) ends each session.

Metaphors and experiential exercises are included in most of the sessions. These comprise an experiential exercise of listening to others, the introduction of values clarification (valued life directions) through the imagery exercise "10 years of marriage" (25), and a psychoeducational component regarding healthy lifestyle (exercise, nutrition, caffeine, alcohol, nicotine, herbal remedies, etc.).

Of the 10 sessions that make up the MBPI, three of them have a different structure from the one just described (husbands are invited to participate in these three sessions).

The first session is mainly introductory, beginning with each person introducing her-/himself. The therapist then addresses the experience of infertility, highlighting what is known about its psychological impact. The aims, contents, and program structure are presented. This first session ends 
with all participants invited to the mindfulness practice "mountain meditation" (51).

The sixth session lasts for one day and takes place on a Saturday or a Sunday. The agenda for the session is presented, and participants get ready for practicing hatha yoga for an hour. A trained yoga teacher conducts this practice following a sequence of yoga postures recommended by Kabat-Zinn in the Mindfulness-Based Stress Reduction Program (20). Before lunch together, participants watch the video The Joy of Stress by Loretta LaRoche. In the afternoon, creativity is encouraged through the exercise "map of life." Although this exercise resembles that of the Mind/Body Program for Infertility (21), its aim is to highlight the importance of values as chosen life directions as well as committing to building patterns of effective action towards a meaningful life (26). After this, each couple is invited to accomplish a communication exercise intended to provide an opportunity for each partner to share her/his feelings about the relationship. To end this session, the mindfulness practice "listening to classical music" (26) is held.

Finally, the eighth session includes invited guests who offer to share their experience. These guests are a couple who has adopted, a couple who has a child conceived with donor gametes, and a couple who has chosen to remain childless. The goal is to provide participants with the contact with different options, fostering debate and exchange of ideas and experiences.

The MBPI sessions were held between May 2009 and May 2010, and according to a previously established rule, women in this group did not miss more than two sessions.

\section{Statistical Analysis}

All quantitative data were analyzed using SPSS (ver. 18; 2010 SPSS Inc.). First, independent samples $t$ tests were conducted to explore whether there were differences between the groups regarding demographic variables. Depending on the nature of clinical variables, the groups were compared through independent samples $t$ tests, $\chi^{2}$-tests, and Fisher tests (52). When significant differences were found, Pearson and point-biserial correlation coefficients were used. Independent samples $t$ tests were also performed to explore the equivalence between the groups regarding the study variables. The effect size considered for these analyses was the eta square $\left(\eta^{2}\right)$, according with Pallant's (53) recommendations. An $\eta^{2}=$ .01 was considered small, $\eta^{2}=.06$ moderate, and $\eta^{2}=.14$ large (54).

To explore mean differences between pretreatment (T1) and post-treatment (T2), between-groups and time $\times$ group interaction effect repeated measures analyses of variance (ANOVAs) were conducted, considering the MBPI and the control group as the between-subjects factor. Mean differences of the study variables were also studied in each group through paired samples $t$ tests. Effect sizes were assessed through partial eta ${ }^{2}\left(\eta^{2} \mathrm{p}\right)$. An $\eta^{2} \mathrm{p} \leq .05$ corresponds to a small effect, $\eta^{2} \mathrm{p}[.05 ; .25]$ to a medium effect, $\eta^{2} \mathrm{p}$ [.25; .50] to a large effect, and $\eta^{2} \mathrm{p}>.50$ to a very large effect (52).

Independent samples $t$ tests and repeated measures ANOVA assumptions were verified through skewness and kurtosis. Sphericity assumption for the repeated measures ANOVAs were analyzed through Mauchly's $W$. Whenever this assumption was not verified, we used the Huynh-Feldt epsilon $(\varepsilon>.75)$ or the Greenhouse-Geisser epsilon $(\varepsilon<.75)$, which correspond to probability correction factors of the F-statistics' significance (55).

A confidence interval of 95\% was used in all the analyses.

\section{RESULTS}

Social demographic and clinical information about the MBPI and control groups is presented in Table 1. The groups were equivalent in years of education and years of marriage. Differences in age were found, but age did not correlate with dependent variables. No significant differences were found regarding clinical variables except for medical treatment previous to the study participation and current medical treatment approach, but these variables did not correlate with dependent variables.

Differences between the groups concerning the study variables were also addressed (Table 2). The MBPI group and the control group did not present significant differences in any of the variables, making them equivalent at baseline.

Group comparisons were conducted based on time and group direct effect as well as on the time $\times$ group interaction effect. As we can see in Table 3, a significant direct effect of time was found for depression, external shame, internal shame, external entrapment, internal entrapment, defeat, psychological inflexibility/experiential avoidance, selfjudgment, and self-efficacy to deal with infertility. Medium effect sizes were found. There were no significant direct time effects regarding self-compassion. No significant direct group effects were found in any of the studied variables.

Significant time $\times$ group interaction effects were found for depression, external shame, internal shame, external entrapment and internal entrapment, defeat, and selfefficacy to deal with infertility, all of them with medium effect sizes. No significant time $\times$ group interaction effects were found in anxiety, psychological inflexibility/experiential avoidance, self-compassion, or self-judgment.

According to Table 4, when comparing mean scores before (T1) and after the program completion (T2) in the MBPI group regarding those variables with significant time $\times$ group effect, a significant decrease was found in: depression, external shame, internal shame, external entrapment, internal entrapment, and defeat. On the other hand, there was a significant increase in self-efficacy to deal with infertility.

Besides those variables with significant time $\times$ group effects, we have also explored mean comparisons before (T1) and after the MBPI (T2) in the two groups, separately, through paired samples $t$ tests. In the MBPI group, there was also a significant decrease in anxiety, experiential avoidance, and self-judgment. No differences were found in self-compassion. As mentioned before, mindfulness skills were also assessed in a subgroup of $30 \mathrm{MBPI}$ participants and a significant increase $[t(54)=-4.24, \quad P<.001$, $\eta^{2}=.38$ ] from $\mathrm{T} 1$ (mean $\left.=34.00, \mathrm{SD}=5.05\right)$ to $\mathrm{T} 2$ (mean $=38.40, \mathrm{SD}=5.57)$ occurred. 


\section{TABLE 1}

\section{Comparisons between the groups regarding demographic and clinical variables.}

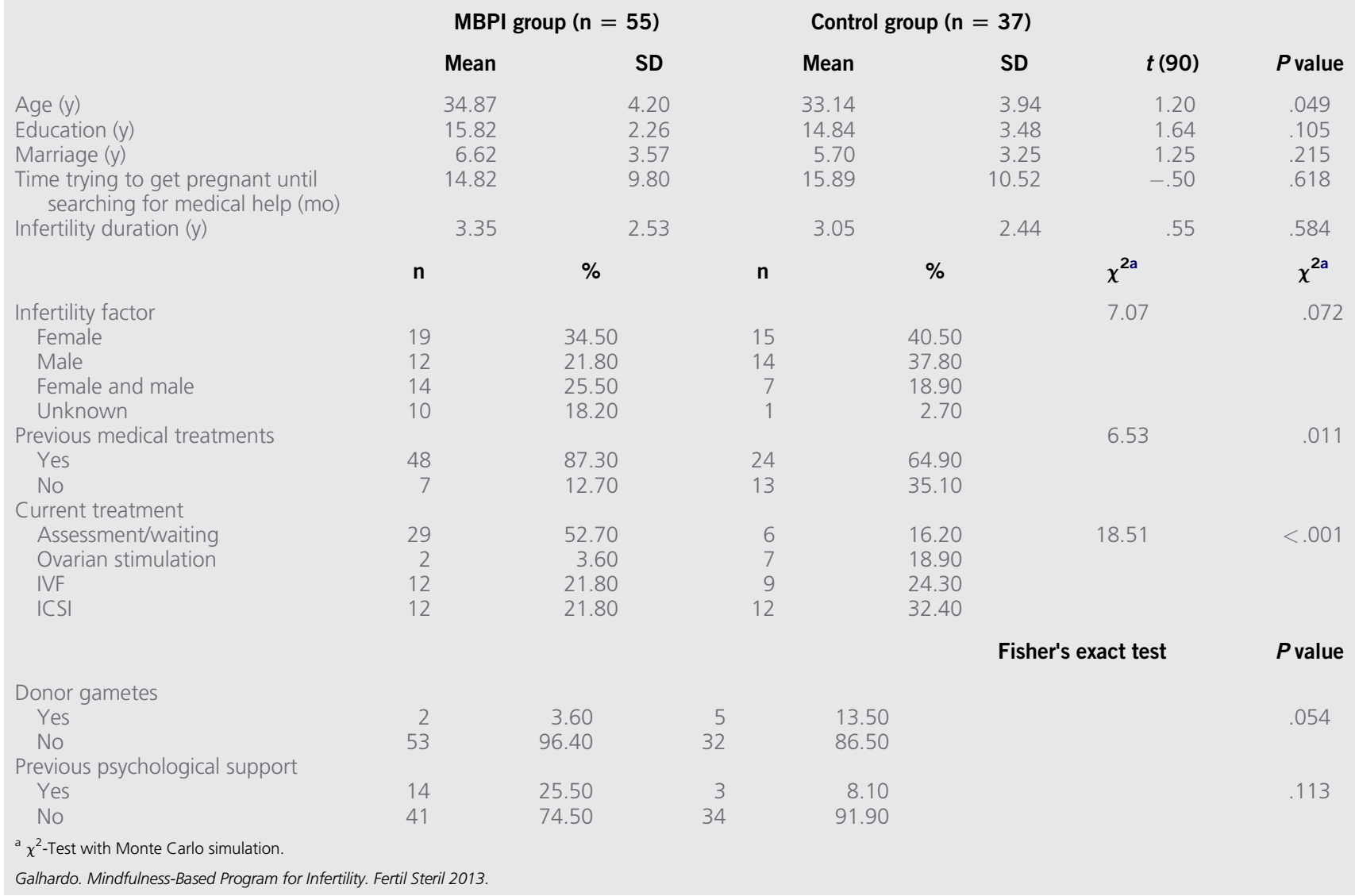

The same analysis was conducted in the control group, and no differences were found in any of the considered variables, except for a significant decrease in self-judgment.

\section{DISCUSSION}

The MBPI is a psychological intervention program that was developed specifically for infertile patients. The overall aim of this study was to examine the efficacy of the MBPI in a sample of infertile women. Several variables were included in the study, and a control group was used for comparison.

When considering the interaction time $\times$ group effect, significant differences were found in terms of depressive symptoms, internal and external shame, internal and external entrapment, and defeat, all of them presenting medium effect sizes. Participants in the MBPI revealed a significant decrease

\section{TABLE 2}

Means, SDs, mean comparisons of the two groups at baseline (T1), and effect size.

\begin{tabular}{|c|c|c|c|c|c|c|c|}
\hline & \multicolumn{2}{|c|}{$\mathrm{PBMI}_{\mathrm{T} 1}(\mathrm{n}=55)$} & \multicolumn{2}{|c|}{ Control group $_{\mathrm{T} 1}(\mathrm{n}=37)$} & \multirow[b]{2}{*}{$t(90)$} & \multirow[b]{2}{*}{$P$ value } & \multirow[b]{2}{*}{$\eta^{2}$} \\
\hline & Mean & SD & Mean & SD & & & \\
\hline $\begin{array}{l}\text { BDI } \\
\text { STAI-Y1 } \\
\text { OAS } \\
\text { ESS } \\
\text { ES } \\
\text { ES } \text { internal } \\
\text { DS } \\
\text { AAQ-II } \\
\text { SCS } \\
\text { SC } \\
\text { ISE } \text { Iudgassion }\end{array}$ & $\begin{array}{r}11.02 \\
47.82 \\
22.22 \\
55.40 \\
8.73 \\
6.78 \\
19.05 \\
23.91 \\
39.65 \\
38.49 \\
81.87\end{array}$ & $\begin{array}{r}7.05 \\
13.09 \\
12.09 \\
17.84 \\
8.72 \\
6.35 \\
10.67 \\
9.10 \\
8.82 \\
10.59 \\
24.45\end{array}$ & $\begin{array}{r}11.35 \\
47.57 \\
18.35 \\
52.08 \\
8.24 \\
4.73 \\
18.24 \\
23.27 \\
41.24 \\
38.78 \\
86.35\end{array}$ & $\begin{array}{r}9.27 \\
15.22 \\
11.93 \\
16.21 \\
8.52 \\
5.64 \\
13.02 \\
8.57 \\
9.29 \\
9.01 \\
26.98\end{array}$ & $\begin{array}{r}-.20 \\
.08 \\
1.51 \\
.91 \\
.26 \\
1.59 \\
.33 \\
.34 \\
-.83 \\
-.14 \\
-.83\end{array}$ & $\begin{array}{l}.845 \\
.933 \\
.134 \\
.367 \\
.793 \\
.116 \\
.744 \\
.736 \\
.409 \\
.891 \\
.411\end{array}$ & $\begin{array}{l}.000 \\
.000 \\
.025 \\
.009 \\
.000 \\
.027 \\
.001 \\
.001 \\
.008 \\
.000 \\
.008\end{array}$ \\
\hline
\end{tabular}

Note: $\mathrm{ES}_{\text {external }}=$ external entrapment; $\mathrm{ES}_{\text {internal }}=$ internal entrapment; $\mathrm{SCS}_{\text {compassion }}=$ self-compassion; $\mathrm{SCS}_{\text {judgment }}=$ self-judgment. 


\section{TABLE 3}

Means, SDs before and after the MBPI, time main effect, group main effect, and time group interaction effect.

\begin{tabular}{|c|c|c|c|c|c|c|c|c|c|c|c|c|c|c|}
\hline \multirow[b]{2}{*}{ Measures } & \multirow[b]{2}{*}{ Time } & \multicolumn{2}{|c|}{ PBMI group $(n=55)$} & \multicolumn{2}{|c|}{ Control group $(n=37)$} & \multicolumn{3}{|c|}{ Time } & \multicolumn{3}{|c|}{ Group } & \multicolumn{3}{|c|}{ Time $\times$ Group } \\
\hline & & Mean & SD & Mean & SD & $\mathbf{F}$ & $P$ & $\eta^{2} p$ & $F$ & $P$ value & $\eta^{2} p$ & $\boldsymbol{F}$ & $P$ value & $\eta^{2} \mathrm{p}$ \\
\hline BDI & $\begin{array}{l}\text { T1 } \\
\text { T2 }\end{array}$ & $\begin{array}{r}11.02 \\
6.18\end{array}$ & $\begin{array}{l}7.05 \\
4.05\end{array}$ & $\begin{array}{l}11.35 \\
10.22\end{array}$ & $\begin{array}{l}9.27 \\
8.79\end{array}$ & 20.99 & $<.001$ & .19 & 2.45 & .121 & .03 & 8.06 & .006 & .08 \\
\hline STAI-Y1 & $\begin{array}{l}\text { T1 } \\
\text { T2 }\end{array}$ & $\begin{array}{l}47.82 \\
43.02\end{array}$ & $\begin{array}{r}13.09 \\
8.70\end{array}$ & $\begin{array}{l}47.57 \\
47.57\end{array}$ & $\begin{array}{l}15.22 \\
14.22\end{array}$ & 2.22 & .140 & .02 & .99 & .323 & .01 & 2.22 & .140 & .02 \\
\hline OAS & $\begin{array}{l}\text { T1 } \\
\text { T2 }\end{array}$ & $\begin{array}{l}22.22 \\
17.09\end{array}$ & $\begin{array}{l}12.09 \\
10.75\end{array}$ & $\begin{array}{l}18.35 \\
18.22\end{array}$ & $\begin{array}{l}11.93 \\
13.26\end{array}$ & 6.66 & .011 & .06 & .35 & .556 & .00 & 5.99 & .016 & .06 \\
\hline ESS & $\begin{array}{l}\text { T1 } \\
\text { T2 }\end{array}$ & $\begin{array}{l}55.40 \\
48.33\end{array}$ & $\begin{array}{l}17.84 \\
14.91\end{array}$ & $\begin{array}{l}52.08 \\
50.62\end{array}$ & $\begin{array}{l}16.21 \\
17.61\end{array}$ & 11.41 & .001 & .11 & .02 & .877 & .00 & 4.94 & .029 & .05 \\
\hline$E_{\text {external }}$ & $\begin{array}{l}\text { T1 } \\
\text { T2 }\end{array}$ & $\begin{array}{l}8.73 \\
5.85\end{array}$ & $\begin{array}{l}8.72 \\
6.60\end{array}$ & $\begin{array}{l}8.24 \\
8.05\end{array}$ & $\begin{array}{l}8.52 \\
9.18\end{array}$ & 7.08 & .009 & .07 & .27 & .603 & .00 & 5.44 & .022 & .06 \\
\hline$E S_{\text {internal }}$ & $\begin{array}{l}\text { T1 } \\
\text { T2 }\end{array}$ & $\begin{array}{l}6.78 \\
4.12\end{array}$ & $\begin{array}{l}6.35 \\
4.86\end{array}$ & $\begin{array}{l}4.73 \\
4.84\end{array}$ & $\begin{array}{l}5.63 \\
5.98\end{array}$ & 5.55 & .021 & .06 & .38 & .540 & .00 & 6.53 & .012 & .07 \\
\hline DS & $\begin{array}{l}\text { T1 } \\
\text { T2 }\end{array}$ & $\begin{array}{l}19.05 \\
14.49\end{array}$ & $\begin{array}{r}10.67 \\
8.24\end{array}$ & $\begin{array}{l}18.24 \\
17.59\end{array}$ & $\begin{array}{l}13.02 \\
14.10\end{array}$ & 7.57 & .007 & .08 & .27 & .606 & .00 & 4.27 & .042 & .05 \\
\hline AAQ-II & $\begin{array}{l}\text { T1 } \\
\text { T2 }\end{array}$ & $\begin{array}{l}23.91 \\
19.64\end{array}$ & $\begin{array}{l}9.10 \\
7.50\end{array}$ & $\begin{array}{l}23.27 \\
21.54\end{array}$ & $\begin{array}{l}8.57 \\
9.93\end{array}$ & 13.27 & $<.001$ & .13 & .15 & .704 & .00 & 2.38 & .126 & .03 \\
\hline SCS & $\begin{array}{l}\text { T1 } \\
\text { T2 }\end{array}$ & $\begin{array}{l}39.70 \\
41.50\end{array}$ & $\begin{array}{l}8.90 \\
8.72\end{array}$ & $\begin{array}{l}41.24 \\
41.08\end{array}$ & $\begin{array}{l}8.65 \\
9.46\end{array}$ & 1.23 & .271 & .01 & .12 & .728 & .00 & 1.77 & .187 & .02 \\
\hline SCS judg & $\begin{array}{l}\text { T1 } \\
\text { T2 }\end{array}$ & $\begin{array}{l}38.49 \\
34.38\end{array}$ & $\begin{array}{r}10.59 \\
8.70\end{array}$ & $\begin{array}{l}38.78 \\
35.97\end{array}$ & $\begin{array}{r}9.01 \\
11.68\end{array}$ & 26.34 & $<.001$ & .23 & .21 & .641 & .00 & .93 & .338 & .01 \\
\hline ISE & T1 & 81.87 & 24.45 & 86.35 & 26.98 & 18.72 & $<.001$ & .17 & .52 & .472 & .01 & 13.88 & $<.001$ & .13 \\
\hline
\end{tabular}

Note: $\mathrm{ES}_{\text {external }}=$ external entrapment; $\mathrm{ES}_{\text {internal }}=$ internal entrapment; $\mathrm{SCS}_{\text {compassion }}=$ self-compassion; $\mathrm{SCS}_{\text {jodgment }}=$ self-judgment.

in these psychopathological measures. Another significant interaction time $\times$ group effect was found regarding the perception of self-efficacy to deal with infertility, which presented a significant increase in women who participated in the program.

Depressive symptoms are related to distorted thoughts about ourselves, and themes of worthlessness and selfblame are rather frequent. Decentering from thoughts and observing them for what they are, merely thoughts and not necessarily corresponding to reality, is one of the skills trained during the MBPI, and this may be a crucial factor for the depressive symptoms reduction (49). Depression is also related to entrapment and defeat, and our results also show a decrease in these variables, meaning that the way these women perceive things in the outside world, as well as their internal feelings and thoughts, induce less escape motivation (35). The perception of being in a struggle and getting defeated by their infertility was also lower, and this may allow a broader perspective (e.g., other family-building options).

Through mindfulness practice, participants became more conscious of their internal and external experience in the present moment with an attitude of openness and curiosity. Thus, painful thoughts and feelings related to the past (e.g., "previous abortion") or to the future (e.g., "I will never be a mother") are recognized without trying to suppress or

\section{TABLE 4}

Mean comparisons at T1 and T2 in the MBPI and in the control group.

\begin{tabular}{|c|c|c|c|c|c|c|c|c|c|c|c|c|c|c|}
\hline & \multicolumn{2}{|c|}{$\begin{array}{l}\text { MBPI group }_{\mathrm{T} 1} \\
\quad(\mathrm{n}=55)\end{array}$} & \multicolumn{2}{|c|}{$\begin{array}{l}\text { MBPI group }_{\mathrm{T} 2} \\
\quad(\mathrm{n}=55)\end{array}$} & \multirow[b]{2}{*}{$t(54)$} & \multirow[b]{2}{*}{$P$ value } & \multirow[b]{2}{*}{$\eta^{2}$} & \multicolumn{2}{|c|}{$\begin{array}{l}\text { Control group } \\
\quad(n=37)\end{array}$} & \multicolumn{2}{|c|}{$\begin{array}{l}\text { Control group } \\
\quad(n=37)\end{array}$} & \multirow[b]{2}{*}{$t(36)$} & \multirow[b]{2}{*}{$P$ value } & \multirow[b]{2}{*}{$\eta^{2}$} \\
\hline & Mean & SD & Mean & SD & & & & Mean & SD & Mean & SD & & & \\
\hline $\begin{array}{l}\text { BDI } \\
\text { STAI-Y1 } \\
\text { OAS } \\
\text { ESS } \\
\text { ES }_{\text {external }} \\
\text { ES } \text { internal } \\
\text { DS } \\
\text { AAQ-II } \\
\text { SCS } \\
\text { SC } S_{\text {judgment }} \\
\text { ISE }\end{array}$ & $\begin{array}{r}11.02 \\
47.82 \\
22.22 \\
55.40 \\
8.73 \\
6.78 \\
19.05 \\
23.91 \\
39.65 \\
38.49 \\
81.87\end{array}$ & $\begin{array}{r}7.05 \\
13.09 \\
12.09 \\
17.84 \\
8.72 \\
6.35 \\
10.67 \\
9.10 \\
8.82 \\
10.59 \\
24.45\end{array}$ & $\begin{array}{r}6.18 \\
43.02 \\
17.09 \\
48.33 \\
5.85 \\
4.13 \\
14.49 \\
19.64 \\
41.44 \\
34.38 \\
98.87\end{array}$ & $\begin{array}{r}4.05 \\
8.70 \\
10.75 \\
14.91 \\
6.60 \\
4.86 \\
8.24 \\
7.50 \\
8.65 \\
8.70 \\
19.58\end{array}$ & $\begin{array}{r}5.46 \\
2.73 \\
3.44 \\
3.95 \\
3.62 \\
3.20 \\
3.37 \\
3.56 \\
-1.77 \\
4.54 \\
-6.00\end{array}$ & $\begin{array}{r}<.001 \\
.009 \\
.001 \\
<.001 \\
.001 \\
.002 \\
.001 \\
.001 \\
.083 \\
<.001 \\
<.001\end{array}$ & $\begin{array}{l}.36 \\
.10 \\
.18 \\
.21 \\
.20 \\
.16 \\
.17 \\
.19 \\
.05 \\
.28 \\
.40\end{array}$ & $\begin{array}{r}11.35 \\
47.57 \\
18.35 \\
52.08 \\
4.73 \\
8.24 \\
18.50 \\
23.27 \\
41.24 \\
38.78 \\
86.35\end{array}$ & $\begin{array}{r}9.27 \\
15.22 \\
11.93 \\
16.21 \\
5.64 \\
8.52 \\
12.15 \\
8.57 \\
9.29 \\
9.01 \\
26.98\end{array}$ & $\begin{array}{r}10.22 \\
47.57 \\
18.22 \\
50.62 \\
4.84 \\
8.05 \\
15.83 \\
21.54 \\
41.08 \\
35.97 \\
87.62\end{array}$ & $\begin{array}{r}8.79 \\
14.22 \\
13.26 \\
17.61 \\
5.98 \\
9.18 \\
10.10 \\
9.93 \\
9.46 \\
11.68 \\
26.88\end{array}$ & $\begin{array}{r}1.28 \\
.00 \\
.12 \\
.94 \\
-.24 \\
.25 \\
1.02 \\
1.89 \\
.17 \\
2.98 \\
-.43\end{array}$ & $\begin{array}{l}.209 \\
1.00 \\
.904 \\
.351 \\
.804 \\
.813 \\
.323 \\
.067 \\
.867 \\
.005 \\
.670\end{array}$ & $\begin{array}{l}.04 \\
.00 \\
.00 \\
.02 \\
.00 \\
.00 \\
.03 \\
.09 \\
.00 \\
.19 \\
.00\end{array}$ \\
\hline
\end{tabular}


modify them. Through metaphors (e.g., bus and passengers metaphor) (22), participants were able to compare their relationship with their own thoughts with that of someone who struggles with these thoughts instead of living their life.

As for internal and external shame, MBPI participants seem to perceive themselves less negatively, as less inadequate, different, unlovable, or unworthy (internal shame). In addition, they seem to see themselves as existing in the mind of the others as someone with less negative characteristics, showing less external shame $(35,56)$.

Perception about their ability to engage in a set of cognitive, emotional, and behavioral skills related to the medical treatment of infertility was also significantly improved in MBPI participants.

When considering mean comparisons within the MBPI group, we also found that participants have decreased anxiety symptoms, self-judgment, and experiential avoidance. They seem to be more capable of accepting their adverse inner mental states (e.g., feelings, thoughts, bodily sensations) and have more psychological flexibility $(26,38)$, which makes them more capable of conscious and deliberate actions, guided by their values, in a flexible and adaptable way (25). Values clarification (chosen life directions) and the use of metaphors and experiential exercises led them to be less focused on their infertility problem and more able to engage in life. Moreover, they tend to feel less isolated, adopt a less self-critical attitude, and be less entangled with their infertility problem.

Women in the control group did not present significant changes in any of the psychological measures, except for self-judgment. Since this corresponds to a sum of isolation, overidentification, and self-criticism, we hypothesize that their participation in the study may have provided a sense of not being alone and of doing something positive for others, which may in turn contribute to a less self-critical attitude. Moreover, half of the participants in this group started medical treatment during the period of the MBPI application, which may have helped them to feel more supported, less isolated, and less identified with the problem. In the MBPI group, 18 (32.7\%) participants started infertility treatment. In fact, it should be mentioned that our control group resembles a waiting list-type control group, and taking action to try to solve their infertility condition, contact with health care providers, having more information about the treatment itself, and developing expectations and hope about the possibility of being a biological mother may play an important role in the observed change (57).

This study entails some other limitations. Participants' recruitment was conducted through the website of the Portuguese Fertility Association, which means that they have Internet access and may be particularly informed and motivated to some kind of psychological intervention. However, since the recruitment procedure was exactly the same for the control group, this topic is less relevant. Another limitation relates to the number of participants. However, analysis of 21 controlled studies on the effectiveness of psychological interventions targeting infertile patients (15) shows that only seven of these studies were conducted on samples of greater size than ours. Participants in both groups were at different stages of their medical treatment and with various indications regarding the medical protocol to be followed, which can be confounders. Even so, results may indicate that the MBPI can be applied to infertility patients regardless of the treatment stage they are in, treatment approach, and infertility history.

By examining this efficacy study on the basis of quality indicators proposed by Hammerli and colleagues (15), we can see that standardized psychological measures were used as dependent variables, the study included an experimental and a control group, and inclusion criteria were established. Although it is not a randomized controlled trial, we emphasize that participants showed equal interest in joining the program and shared similarities (primary infertility diagnosis, access to the Internet). The criteria for their distribution to the experimental or the control group was of a geographical nature, and participants in the control group were given the opportunity to participate in future MBPI editions. Since there are 10 public clinics and 16 private clinics in Portugal and they are fairly well distributed in the north, center, and south of the country, participants in both groups were medically assisted more or less in the same clinics, decreasing the probability of eventual influences of geographical differences. Furthermore, the groups did not present significant differences in demographics and were equivalent at baseline regarding the psychological measures used. In general, the probability of systematic differences in comparison groups at baseline was low, diminishing the risk of selection bias (58). The low attrition rate is also worth noting.

This was not a blind study given the nature of practical impediments to collecting the sample. The dropout rate before group allocation did not exceed $12.2 \%$, which is favorable (values below 20\% are considered good). Throughout the study, considering baseline assessment and post-MBPI, there was no attrition bias.

Our findings suggest that the MBPI is an effective psychological intervention for women experiencing infertility. Effects were found on several measures, not only regarding psychopathology, but also in terms of emotion regulation processes, mindfulness skills, and the way participants perceive their ability to cope with the demands of infertility and its medical treatment. In fact, this program seems to particularly contribute to a decrease in depressive symptoms and an increase in patients' mindfulness skills and perception of their own ability to deal with infertility in a favorable manner. Preliminary data also point to the maintenance of therapeutic gains at a 6-month follow-up, and further research is being carried out in this context.

Thus, despite the limitations mentioned, results point to the effectiveness of the MBPI. To our knowledge, this is the first program that focuses specifically on mindfulness and acceptance skills designed for people with infertility, and we expect that its pioneering nature will stimulate the interest and curiosity of researchers and clinicians to extend its application. The MBPI can contribute to minimizing suffering and the negative consequences that infertility and its treatment trigger and help these patients to live a more vital, flexible, and values-based life and be less focused on infertility. 
Acknowledgments: The authors thank all the participants in the study for their contribution. The authors would also like to thank the Portuguese Fertility Association for the support provided.

\section{REFERENCES}

1. Menning BE. The emotional needs of infertile couples. Fertil Steril 1980;34: 313-9.

2. Burns LH, Covington SN. Psychology of infertility. In: Covington SN, Burns LH, editors. Infertility counseling a comprehensive handbook. New York: Cambridge University Press; 2006:1-19.

3. Wischmann T, Stammer H, Scherg H, Gerhard I, Verres R. Psychological characteristics of infertile couples: a study by the Heidelberg Fertility Consultation Service. Hum Reprod 2001;16:1753-61.

4. Chen TH, Chang SP, Tsai CF, Juang KD. Prevalence of depressive and anxiety disorders in an assisted reproductive technique clinic. Hum Reprod 2004;10: 2313-8.

5. Cohen J, Cohen P, West S, Aiken L. Applied multiple regression/correlation analysis for behavioural sciences. $3 d$ ed. New Jersey: Lawrence Erlbaum Associates; 2003.

6. Eugster A, Vingerhoets AJJM. Psychological aspects of in vitro fertilization: a review. Soc Sci Med 1999;48:575-89.

7. Greil A. Infertility and psychological distress: a critical review of the literature. Soc Sci Med 1997;45:1679-704

8. Verhaak CM, Lintsen AME, Evers AWM, Braat DDM. Who is at risk of emotional problems and how do you know? Screening of women going for IVF treatment. Hum Reprod 2010;25:1234-40

9. Verhaak CM, Smeenk JMJ, Evers AWM, Kremer JAM, Kraaimaat FW Women's emotional adjustment to IVF: a systematic review of 25 years of research. Hum Reprod 2007;13:27-36.

10. Volgsten H, Svanberg AS, Ekselius L, Lundkvist Ö, Poromaa IS. Prevalence of psychiatric disorders in infertile women and men undergoing in vitro fertilization treatment. Hum Reprod 2008;23:2056-63.

11. Ramazanzadeh F, Noorbala AA, Abedinia N, Naghizadeh MM. Emotional adjustment in infertile couples. Iran J Reprod Med 2009;7:97-103.

12. Brandes $M$, van der Steen JO, Bokdam SB, Hamilton CJ, de Bruin JP, Nelen $W L$, et al. When and why do subfertile couples discontinue their fertility care? A longitudinal cohort study in a secondary care subfertility population. Hum Reprod 2009;24:3127-35.

13. Boivin J. A review of psychosocial interventions in infertility. Soc Sci Med 2003;57:2325-41.

14. deLiz TM, Strauss B. Differential efficacy of group and individual/couple psychotherapy with infertile patients. Hum Reprod 2005;20:1324-32.

15. Hammerli K, Znoj H, Barth J. The efficacy of psychological interventions for infertile patients: a meta-analysis examining mental health and 370 pregnancy rate. Hum Reprod Update 2009;15:279-95.

16. Chan CHY, Chan CLW, Ng EHY, Ho PC, Chan THY, Lee GL, et al Incorporating spirituality in psychosocial group intervention for women undergoing in vitro fertilization: A prospective randomized controlled study. Psychol Psychother Theory Res Prac 2012;85:356-73.

17. Domar AD, Rooney KL, Wiegand B, Orav EJ, Alper MM, Berger BM, et al. Impact of a group mind/body intervention on pregnancy rates in IVF patients. Fertil Steril 2011;95:2269-73.

18. Korszycki D, Bisserbe J-C, Blier P, Bradwedjn J, Markowitz J. Interpersonal psychotherapy versus brief supportive therapy for depressed infertile women: first pilot randomized controlled trial. Arch Women's Mental Health 2012;15:193-201.

19. Baer RA. Mindfulness training as a clinical intervention: a conceptual and empirical review. Clin Psychol Sci Pract 2003;10:125-43.

20. Kabat-Zinn J. Full catastrophe living. New York: Delta; 1990.

21. Domar AD, Seibel MM, Benson $H$. The mind/body program for infertility: a new behavioral treatment approach for women with infertility. Fertil Steril 1990;53:246-9.

22. Hayes SC, Stroshal KD, Wilson KG. Acceptance and commitment therapy: an experiential approach to behavior change. New York: Guilford Press; 1999.
23. Luoma JB, Hayes SC, Walser RD. Learning ACT-an acceptance and commitment therapy skills-training manual for therapists. Oakland: New Harbinger Publications; 2007.

24. Ciarrochi JV, Bailey A. A CBT practitioner's guide to ACT-how to bridge the gap between cognitive behavioral therapy and acceptance and commitment therapy. Oakland: New Harbinger Publications; 2008.

25. Harris R. ACT made simple: a quick-start guide to ACT basics and beyond. Oakland: New Harbinger Publications; 2009.

26. Hayes SC, Smith S. Get out of your mind and into your life: the new acceptance and commitment therapy. Oakland: New Harbinger Publications; 2005

27. Beck A, Ward C, Mendelson M, Mock J, Erbaugh J. An inventory for measuring depression. Arch Gen Psychiatry 1961;4:561-71.

28. Vaz-Serra A, Pio-Abreu JL. Aferição dos quadros clínicos depressivos —-estudo de aplicação do "Inventário Depressivo de Beck" a uma amostra portuguesa de doentes deprimidos. Coimbra Médica 1973a;20: 623-44.

29. Vaz-Serra A, Pio-Abreu JL. Aferição dos quadros clínicos depressivos ॥-estudo preliminar de novos agrupamentos sintomatológicos para complemento do "Inventário Depressivo de Beck." Coimbra Médica 1973b;20:713-36

30. Spielberg CD. Manual for State-Trait Anxiety Inventory (Form Y). Palo Alto: Consulting Psychologists Press; 1973.

31. Daniel F. Teoria e prática psicométrica—contribuição para a validação do STAI-Y de Spielberger em estudantes do ensino superior. Badajoz: Universitá de Extremadura 1996.

32. Goss K, Gilbert P, Allan S. An exploration of shame measure: the "others as shamer scale". Personal Individ Diff 1994;17:713-7.

33. Matos M, Pinto-Gouveia J. Shame as a traumatic memory. Clin Psychol Psychother 2010;17:299-312.

34. Andrews B, Qian M, Valentine J. Predicting depressive symptoms with a new measure of shame: the experience of shame scale. Br J Clin Psychol 2002;41: 29-42.

35. Gilbert $P$, Allan $S$. The role of defeat and entrapment (arrested flight) in depression: an exploration of an evolutionary view. Psychol Med 1998;28: 585-98.

36. Carvalho S, Pinto-Gouveia J, Castilho P, Pimentel P. Entrapment-conceito, definição e características psicométricas da versão portuguesa da Escala de Entrapment. Psychologica 2011;54:385-412.

37. Carvalho S, Pinto-Gouveia J, Castilho P, Pimentel P, Maia D. Derrotaconceito e avaliação: características psicométricas da versão portuguesa da Escala de Derrota (Defeat Scale). Psychologica 2011;54:465-92.

38. Bond FW, Hayes SC, Baer RA, Carpenter KC, Guenole N, Orcutt HK, et al. Preliminary psychometric properties of the Acceptance and Action Questionnaire II: a revised measure of psychological flexibility and acceptance. Behav Ther 2011;42:676-88.

39. Pinto-Gouveia J, Gregório S, Dinis A, Xavier A. Experiential avoidance in clinical and nonclinical samples. Intl J Psychol Psychol Ther 2012;12:139-56.

40. Neff K. The development and validation of a scale to measure selfcompassion. Self Ident 2003;2:223-50.

41. Castilho P, Pinto-Gouveia J, Bento E. Autocompaixão: estudo da validação da versão portuguesa da Escala da Autocompaixão e da sua relação com as experiências adversas na infância, a comparação social e a psicopatologia. Psychologica 2011;54:203-30.

42. Cousineau TM, Green TC, Corsini EA, Barnard T, Seibring AR, Domar AD Development and validation of the Infertility Self-Efficacy scale. Fertil Steril 2006;85:1684-96

43. Galhardo A, Cunha M, Pinto-Gouveia J. Measuring self-efficacy to deal with infertility: psychometric properties and confirmatory factor analysis of the Portuguese version of the Infertility Self-efficacy Scale. Res Nurs Health 2013;36:65-74.

44. Walach $\mathrm{H}$, Buchheld $\mathrm{N}$, Buttenmuller $\mathrm{V}$, Kleinknecht $\mathrm{N}$, Schmidt $\mathrm{S}$ Measuring mindfulness - the Freiburg Mindfulness Inventory (FMI). Personal Individ Diff 2006:40:1543-55.

45. Segal ZV, Williams JMG, Teasdale JD. Mindfulness-based cognitive therapy for depression: a new approach to preventing relapse. New York: Guilford Press; 2002. 
46. Crane R. Mindfulness-based cognitive therapy. London: Routledge; 2009.

47. Williams $M$, Penman D. Mindfulness: a practical guide to finding peace in a frantic world. London: Piatkus; 2011.

48. Walser RD, Westrup D. Acceptance and commitment therapy for the treatment of post-traumatic stress disorder and trauma-related problems: a practitioner's guide to using mindfulness and acceptance strategies. Oakland: New Harbinger Publications; 2007.

49. Williams M, Teasdale J, Segal Z, Kabat-Zinn J. The mindfulness way through depression. New York: Guilford Press; 2007.

50. Forsyth JP, Eifert GH. The mindfulness and acceptance workbook for anxiety: a guide to breaking free from anxiety, phobias and worry using acceptance and commitment therapy. Oakland: New Harbinger Publications; 2007.

51. Siegel RD. The mindfulness solution-everyday practices for everyday problems. New York: Guilford Press; 2010.

52. Marôco J. Análise Estatística com o PASW Statistics. Lisboa: ReportNumber Lda; 2010.
53. Pallant J. SPSS survival manual: a step by step guide to data analysis with SPSS. 4th ed. Crows Nest: Allen \& Unwin; 2011.

54. Cohen J. Statistical power analysis for the behavioral sciences. $2 d$ ed. New Jersey: L. Erlbaum Associates; 1988.

55. Field AP. Discovering statistics using SPSS: (and sex, drugs and rock ' $n$ ' roll). 3d ed. Los Angeles: SAGE Publications; 2009.

56. Gilbert P. Body shame: a biopsychosocial conceptualization and overview, with treatment implications. In: Gilbert P, Miles J, editors. Body shame: conceptualization, research and treatment. London: Brunner; 2002:3-54.

57. Spokas ME, Rodebaugh TL, Heimberg RG. Treatment outcome research. In: McKay D, editor. Handbook of research methods in abnormal and clinical psychology. Los Angeles: Sage Publications; 2008:513-30

58. Deeks JJ, Dinnes J, D'Amico R, Sowden AJ, Sakarovitch C, Song F, et al. Evaluating non-randomized intervention studies. Health Technol Assess 2003;7:1-6. 